\title{
CHARGE: GÊNERO DISCURSIVO E SEU USO EM SALA DE AULA
}

\section{Susy Ferreira Gomes ${ }^{1}$}

RESUMO: As charges acompanham e marcam época, servem para compreender o lado crítico do cenário político e social de cada sociedade e trazem o espírito de um tempo com suas diversas camadas de sentidos, seja o ideológico, cultural ou político, essas não são apenas um símbolo ou manifesto subjetivo do cartunista, mas uma representação de grupos sociais. As charges, como instrumento de reflexão e fonte/objeto de pesquisa podem ser consideradas e analisadas como produto da história, como resultado da técnica da produção de imagens e da própria imprensa. $\mathrm{O}$ professor, ao conduzir a análise das charges em sala de aula, está contribuindo para que os sujeitos da aprendizagem se apropriem das habilidades e competências para a prática da leitura e interpretação de textos. Partindo dos pressupostos teóricos de Mikhail Bakhtin (2003), sob a perspectiva da linguagem como construção social, dialógica, e os conceitos de gênero discursivo, o presente trabalho utilizará charges como gêneros que compõem o processo de ensino e aprendizagem. Assim o utilizaremos charges exemplificando o seu uso didaticamente no ensino de História, e possibilidades de seu uso em sala de aula.

PALAVRAS-CHAVES: Charge. Gênero discursivo. Sala de aula.

\section{Introdução}

A charge - do francês charger: carregar, exagerar- é um desenho singular, que possui relação com demais desenhos gráficos - caricatura e cartum - e com os quais às vezes é confundida. Mas que em sua estrutura e função possui características únicas, como "um desenho sem inibições que abre uma brecha na cultura e cria um espaço de repressão no cotidiano do jornal e do leitor" (TEIXEIRA, 2005, p. 14).

Esse desenho é a articulação que existe entre diferentes linguagens, especialmente a verbal e a visual, possui o humor e irreverência como umas de suas ferramentas, e atua como instrumento de reflexão e crítica. Em uma charge podem conter a caricatura como um de seus elementos, como também espaço, o plano, o ponto de enfoque, o volume, a luz e a sombra, o movimento, a narrativa, o balão, a onomatopeia e o texto verbal, não aparecendo necessariamente, todos estes elementos em todas as charges (MIANI, 2001).

Além do riso, a charge e a caricatura políticas podem causar também ao intérprete um estranhamento, pois podem despertar sua consciência, dar uma visão do político ou da situação que desconhecia, ou seja, desvendar, desnudar uma

\footnotetext{
1 Mestra em História pela Universidade Federal do Maranhão - UFMA. E-mail: susynathia@gmail.com
} 
realidade que talvez não quisesse ver ou conhecer. Do modo que, a charge e a caricatura política possuem um grau de ambiguidade, uma carga emocional que a caricatura comum, a charge comum, a de costumes e de humor não contêm. Mais que o riso, a caricatura política visa destruir a imagem do caricaturado, mostrando a verdadeira face, seu verdadeiro caráter, destacando o que a mídia e o personagem buscavam esconder (GAWRYSZEWSKI, 2008).

\title{
Gênero charge
}

Mikhail Bakhtin (2003) trata da linguagem relacionada ao âmbito social, pensa a questão do gênero não apenas na ordem do linguístico ou do texto, mas principalmente na ordem do enunciável, isto é, ele propõe compreender as razões histórico-sociais pelas quais surge um gênero.

A charge mesmo tendo em sua estrutura elementos verbais e não-verbais, pode ser considerada um gênero discursivo, por sua função social de comunicar, e assim como os demais gêneros discursivos, a charge é um "dispositivo de organização, troca, divulgação, armazenamento, transmissão e, sobretudo, de criação de mensagens em contextos culturais específicos" (BRAIT, 2007, p. 158).

Segundo Bakhtin:

\begin{abstract}
Em cada campo existem e são empregados gêneros que correspondem às condições específicas de dado campo. Uma determinada função e determinadas condições de comunicação discursiva, específicas de cada campo, geram determinados gêneros, isto é, determinados tipos de enunciados estilísticos, temáticos e composicionais relativamente estáveis (BAKHTIN, 2003, p. 266).
\end{abstract}

Assim, o gênero é relativamente estável, mas essa estabilidade não é sempre presente, haja vista que há forças que atuam sobre as restrições genéricas, forças de caráter cultural, social e individual que determinam ou causam mudanças em um gênero.

No humor gráfico é possível uma maior intervenção do sujeito e inscrição de um estilo mais individual, por ser um gênero que provoca rupturas em relação ao esperado. As charges têm como suporte um veículo midiático, que segue também esquemas pré-estabelecidos, e variações estilísticas. Do modo que a sua a função é de comunicação e crítica, tal gênero desde sua criação tratou de temas relacionados à política e a assuntos diversos, elaborado por determinada esfera da 
atividade humana - a jornalística e artística-, relacionada com o momento histórico em que foi produzida.

Ao analisar e interpretar as charges considerarei os argumentos de Flôres, no qual destaca que o discurso chargístico dirige-se a sujeitos socialmente situados, ou seja, a sujeitos já inscritos na ideologia, assim, sujeitos que participam na construção do sentido, de forma que o cartunista ao elaborar uma charge, informa e opina sobre determinado assunto, ironizando e criticando de forma humorística (FLÔRES, 2002, p. 11).

De acordo com Bakhtin, "cada enunciado é pleno de ecos e ressonâncias de outros enunciados com os quais está ligado pela identidade da esfera de comunicação discursiva" (BAKHTIN, 2003, p. 297), assim é o discurso elaborado nas charges, com uma interdiscursividade com outros discursos, pois ela comumente contém informações que constituem matérias e reportagens, abordando um acontecimento já mencionado por outros textos.

\section{Charge na sala de aula}

Os materiais didáticos podem ser compreendidos como mediadores do processo de aquisição de conhecimento, facilitadores da apreensão de conceitos e do domínio de informações. Circe Maria destaca que dentre a diversidade de materiais didáticos há diferenças que devem ser abordadas. Suportes informativos e os "documentos" foram denominações que o INRP (Institut National de Recherche Pédagogique) da França indicou, ressaltando diferenças importantes (BITTENCOURT, 2004).

Os suportes informativos são os recursos produzidos com a intenção de comunicar elementos do saber e das disciplinas escolares, pertencem ao setor da indústria cultural e são produzidos especialmente para a escola, caracterizado por uma linguagem própria, por um tipo de construção técnica que obedece a critérios de idade (BITTENCOURT, 2004). "Os documentos, diferentemente dos suportes informativos, foram produzidos inicialmente sem intenção didática, almejando atingir um público mais amplo e diferenciado " (BITTENCOURT, op. cit., p. 297).

A escolha dos recursos didáticos está relacionada às concepções sobre 0 conhecimento do educador, de como o aluno vai apreendê-lo e do tipo de formação que pode ser oferecida. $O$ uso de imagens é uma das formas mais eficazes 
utilizadas como recurso pedagógico no ensino, para incrementar o processo de aprendizagem. E são muitos os meios que se apresentam para esta utilização: vídeo documentários, cinema, pintura, fotografia, música, mapa, internet, história em quadrinhos, arquitetura, charges, e etc.

Dentre a variedade de subsídios teóricos incorporados por alguns profissionais da educação, a introdução do uso da imagem em sala de aula, entre outras linguagens, se constituem ferramentas indispensáveis para que os alunos aprendam a ler e interpretar não apenas signos, mas principalmente o mundo ao seu redor, que é de fundamental importância no processo de ensino-aprendizagem, tornando-o ainda mais prazeroso e possibilitando transmitir maior conhecimento, não limitando o aluno apenas no livro didático.

Quando se fala sobre a incorporação de novas linguagens ao ensino de História, Selva Guimarães Fonseca (2007) afirma, que incorporar diferentes linguagens no processo de ensino de História não só estreita a ligação entre saberes escolar e a vida social, mas também a necessidade de reconstruirmos nosso conceito de ensino e aprendizagem.

O material imagético que é utilizado nos livros didáticos, paradidáticos, tanto quanto nos ambientes virtuais, revistas, jornais impressos servem na construção de conceitos que são assimilados pela sociedade como reais. Problematizar questões que são abordadas por estes, sejam elas atuais ou de outras épocas, é uma estratégia de ensino positiva, pois desmistifica estereótipos, amplia a visão crítica do educando e propicia uma atitude reflexiva.

As imagens não se esgotam em si mesmas, há sempre algo que pode ser apreendido, bem como suscitar diversas discussões, sobre as condições de produção, contexto social em que estavam inseridas, a representação para o período e sociedade. De acordo com Eduardo Paiva (2002), o bom professor de história tem que ser também um bom historiador, sabendo lidar criticamente, em todos os níveis de ensino, com as fontes, sejam elas as mais distintas. "Lidar com essa diversidade de registros, saber indagá-los e desconstruí-los, saber contextualizá-los e explorá-los ...apropriarmo-nos criticamente deles e usá-los metodologicamente" (PAIVA, op. cit., p. 13).

A charge é uma forma de comunicação condensada com muitas informações, em que o entendimento depende de um conjunto de dados e fatos 
contemporâneos ao momento específico em que se estabelece a relação discursiva entre o produtor e o receptor, e aliada ao humor atrai o leitor para uma crítica de forma descontraída, como cita Romualdo (2000):

\begin{abstract}
Se pensarmos em termos de conteúdo, uma charge ou uma caricatura podem ser muito mais densas do que os outros textos opinativos, como uma crônica ou até mesmo um editorial. O leitor pode, inclusive, deixar de ler estes e outros gêneros opinativos convencionais, optando pela leitura da charge que, por ser um texto imagético e humorístico, atrai mais sua atenção e the transmite mais rapidamente um posicionamento crítico sobre personagens e fatos políticos (ROMUALDO, 2000, p. 15).
\end{abstract}

Assim, a sua característica humorística promove um maior interesse por parte dos alunos que, ao analisá-las, desenvolverão uma visão crítica a respeito do assunto que a mesma aborda e, ao mesmo tempo, trabalhará tanto a aprendizagem bem como com a socialização de conhecimentos, permitindo que o aluno passe a entender a imagem como discurso, atribuindo-Ihe sentidos sociais e ideológicos (LITZ, 2009).

O uso da charge em sala de aula deve ter uma ligação direta com o conteúdo em foco, como aconselha Litz:

\begin{abstract}
O professor deve ter objetivos pedagógicos em relação à escolha do material a ser trabalhado, para que este não se perca durante o processo e consiga trocar informações sobre o conteúdo que está sendo passado. Pode ser utilizada - a charge - para introduzir um capítulo ou um assunto novo, ou após a discussão do mesmo, o que é mais comum, pois assim o aluno já terá um conhecimento mais amplo para realizar uma análise de forma mais concreta. Pode ser associada a textos escritos e em avaliações, quando o aluno poderá articular informações, interpretando-a de acordo com o que foi estudado (LITZ, 2009, p. 33).
\end{abstract}

\title{
Charge no ensino de História
}

Com as mudanças advindas dos avanços tecnológicos, bem como o alcance e uso das novas tecnologias da informação e da comunicação nos sistemas de ensino, que oferecem aos educandos o acesso a computadores e outros dispositivos eletrônicos como alternativas na melhoria da aquisição de conhecimentos, dinamizando o processo de ensino aprendizagem.

Ao conduzir a análise das charges e tirinhas em sala de aula, o professor está contribuindo para os sujeitos da aprendizagem se apropriem das habilidades 
e competências para que a prática da leitura e interpretação de textos se realize de forma crítica e reflexiva. A utilização da charge em sala de aula possibilita que o aluno consiga unir conceitos, conteúdos e normas ao conhecimento do que lhe cerca, contribuindo para que o aprendizado não seja passageiro, que se mantenha e evolua conforme as novas informações forem recebendo ao longo de sua formação.

O professor deve ter objetivos pedagógicos em relação à escolha do material a ser trabalhado, para que este não se perca durante o processo de compreensão e de interpretação. Pois a charge como recurso didático ajuda o aluno adentrar outros universos, conhecer outros discursos, debater sobre sua realidade e ter novas maneiras de expressar uma opinião, ampliando também sua forma de leitura. Pois de acordo com Lajolo:

\footnotetext{
Ler não é decifrar, como num jogo de adivinhações, o sentido de um texto. É a partir do texto, ser capaz de atribuir-lhe significado, conseguir relacioná-lo a todos os outros textos significativos para cada um, reconhecer nele o tipo de leitura que seu autor pretendia e, dono da própria vontade, entregar-se a esta leitura, ou rebelar-se contra ela, propondo outra não prevista (LAJOLO, 1993, p. 59).
}

O processo de leitura não se restringe ao ato de decodificar os signos dispostos nos livros e outros gêneros textuais, as atividades de leitura e análise devem levar os alunos a perceber a composição das charges, bem como a sua função social e seus propósitos comunicativos. Outra vantagem do uso da charge como recurso didático está no fato desta chamar a atenção dos alunos pela própria linguagem artística que exibe, assim como as inúmeras abordagens sobre a política nacional e internacional, estabelecendo relações de intertextualidade, evocando conhecimentos específicos da linguagem e do período histórico a ser analisado.

No de ensino de história, o professor deve criar condições para que o aluno possa ter autonomia nas suas reflexões, reconhecendo que "o conhecimento histórico não é adquirido como um dom" (SCHMIDT, 2004, p. 57) e sim por meio de pesquisas e de redescobertas. A sala de aula não é um simples espaço de transmissão de informações, mas antes um ambiente de vivências, de experiências, uma construção de sentidos e significações.

Durante o período da ditadura militar no Brasil -1964 a 1985- as charges tiveram destaque como forma de contestação, ocuparam lugar significativo e 
expressivo nas lutas, nos movimentos sociais, políticos e culturais da sociedade brasileira, gerando discussões quanto aos anseios da construção de uma sociedade democrática e cidadã.

Esse trabalho tem como recorte o período de Abertura política, redemocratização no Brasil, tendo em vista que o uso de charges que circularam nesse período possibilita trabalhar os conceitos de democracia, ditadura militar, os movimentos sociais, políticos e culturais, principalmente pela proximidade do tempo histórico. Também se levou em consideração a grande produção de charges neste momento histórico da sociedade brasileira.

A historiografia brasileira, no referido período, tem material diversificado e rico para a investigação histórica. A charge revela-se como um traço da história, pois captura os fatos, denunciando faces do poder por meio de uma linguagem metafórica, assim fazendo parte da memória histórica. A memória é um fenômeno sempre atual, e muitas das charges que circularam nesse período servem hoje de análise e reflexões sobre o que passou.

As charges a seguir, são ilustrações que circularam na imprensa teresinense - Jornal O Dia - durante o governo de João Batista Figueiredo (1979-1985) e podem servir para análise e compreensão do processo de abertura política. $\mathrm{Na}$ ilustração 01 , os dois personagens junto das ferraduras aparentam meio desagradados da Abertura, assim como as afirmações irônicas que acompanham a charge.

"Haverá abertura", o uso das ferraduras na ilustração está relacionado ao presidente Figueiredo. Do modo que é recorrente nas charges, desse período, o uso das ferraduras, senão a imagem do próprio cavalo relacionando com a abertura ou com o presidente. 


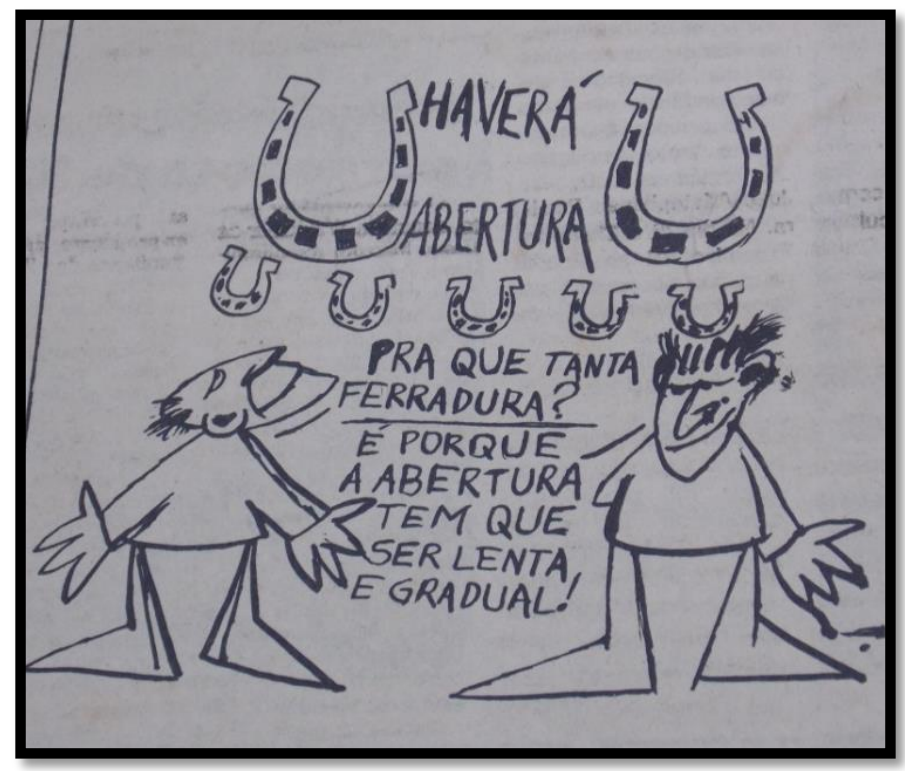

1. Jornal O Dia, 18 de janeiro de 1979.

"Pra que tanta ferradura?", de acordo com o contexto e a referência com o presidente, o questionamento pode ser entendido, como: "pra que tanta grosseria, ou ainda estupidez?". Assim, entendemos que o fato da abertura ser lenta e gradual é tido como algo estúpido e sem sentido. Pois se o resultado final é a democratização, por que não realizá-la de uma vez?

Após a observação da charge, o aluno deve fazer uma análise do que leu, e aos detalhes e conteúdo da ilustração. Indagando: Qual mensagem a charge quer passar? Qual o posicionamento que o discurso da propõe? O ano da charge condiz com a temática abordada?

A charge em questão é uma crítica a abertura política, que era essencialmente uma estratégia dos detentores do poder, que por meio de concessões liberalizantes objetivavam acalmar a sociedade e garantir a manutenção do poder, bem como uma perpetuação da ditadura através da improvisação de um "regime de transição" (BRESSER-PEREIRA, 1988, p. 20). Essa liberalização outorgada nada mais era que um fator de continuidade, não para superar a ordem autoritária, mas para institucionalizá-la (FLORESTAN, 1982, p. 28). 


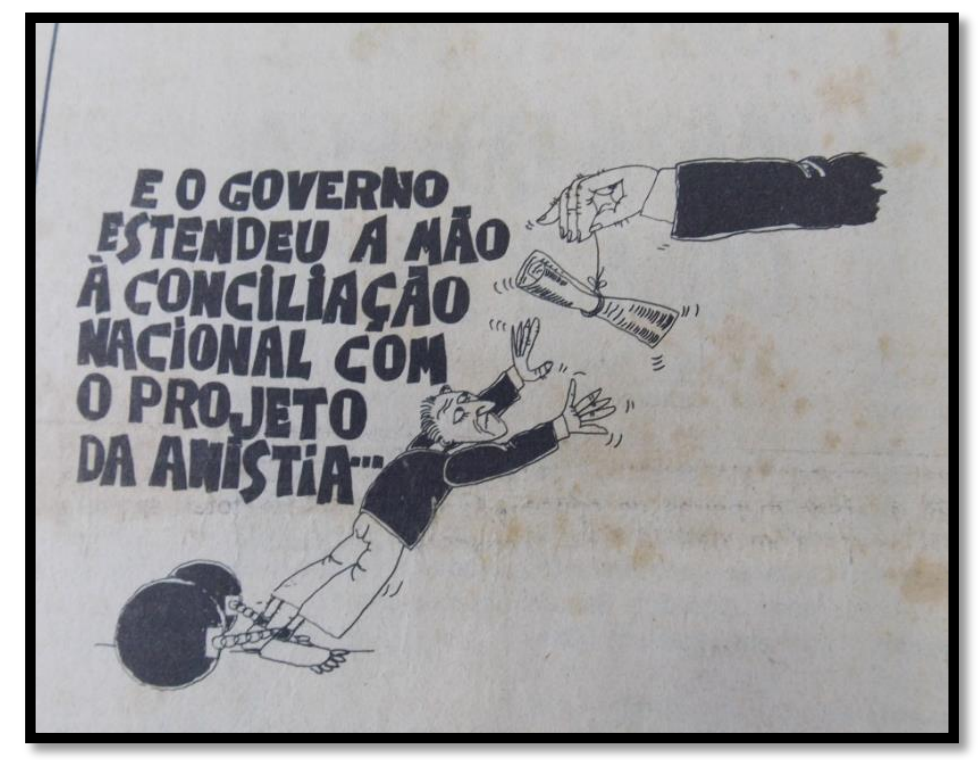

II. Jornal O Dia, 13 de julho de 1979.

As charges podem convencer e até influenciar um leitor, tornando-o mais crítico e consciente de sua realidade. O professor pode utilizá-la para exercer sua função de formador de opinião, bem como orientar o aluno para que ele possa conhecer outras possibilidades de conhecimento de mundo. Haja vista que o importante não é apenas identificar o que está apresentado, mas suscitar e solucionar respostas.

Na charge II, "Estender a mão" pode ser entendido como um ato de auxílio, ajuda ou amparo, refere-se ao dia em que ocorreu o pleito para presidente, 15 de outubro de 1978, no qual Figueiredo foi eleito. E assim lançou uma proclamação ao povo brasileiro, que dizia: "Reconheço que a disputa é própria dos regimes abertos, das instituições sadias. Travado o pleito, porém, quero apresentar ao povo a mensagem que é a própria expressão do caráter nacional: a minha mão estendida em conciliação." 2

$\mathrm{Na}$ ilustração, o personagem pode ser entendido como um preso político, com a presença dos grilhões nos pés, tentando alcançar o projeto de anistia estendido pela superior “mão" do governo, como está sendo descrito pela própria imagem.

O texto que complementa a charge é finalizado com reticências, dando a ideia de que ele se conclui com a imagem. De modo que na premissa: "E o governo

\footnotetext{
2 Informação disponível em: http://www.fgv.br/cpdoc/acervo/dicionarios/verbete-biografico/joaobatista-de-oliveira-figueiredo.
} 
estendeu a mão à conciliação nacional com o projeto da anistia...", entra em correspondência com a imagem, que entendida pela forma como a mão está estendida, segurando nas pontas do dedo o projeto, dificultando o alcance, remete à ineficiência do mesmo, não apenas pela proposta de anistia, parcial e restrita, a qual o governo elaborou no projeto, como também ao outro motivo que está relacionado ao ato do governo de estender a mão: a conciliação nacional, relativo à tradição da anistia na política brasileira, da conciliação como meio para manutenção dos interesses das classes dominantes, a da contrarrevolução preventiva como estratégia anticrises (LEMOS, 2002, p. 289-293).

A imagem III, refere-se à "comemoração" do aniversário de 15 anos do golpe de 1964, faz menção não apenas ao acontecimento, mas ao presidente em gestão. O uso dessa charge em sala de aula pode suscitar alguns questionamentos, como: Haviam comemoração ao golpe? O porquê do termo revolução? Qual o sentindo de revolução para a época? O que o cartunista quis informar sobre essa charge?

O uso do eufemismo revolução refere-se ao golpe, destacando que a charge data de 01/02 de abril de 1979. Na ilustração, aparece o "re" separado de "volução", re-volução, que colocado diante do espelho reflete a palavra "RE-VOLUÇÃO", e com os rastros de cavalo, pode ser entendido que a 're-volução' refletem 15 anos de grosserias, de repressões, truculências e todos os atos digno de um cavalo.

Essa charge nos faz lembrar que, os sentidos não estão apenas nas palavras, nos textos, como também na relação com a exterioridade, pois os dizeres não são apenas mensagens a serem decodificadas (ORLANDI, 2000,p. 30). São efeitos de sentidos que são produzidos em condições determinadas e que estão de alguma forma presentes no modo como se diz.

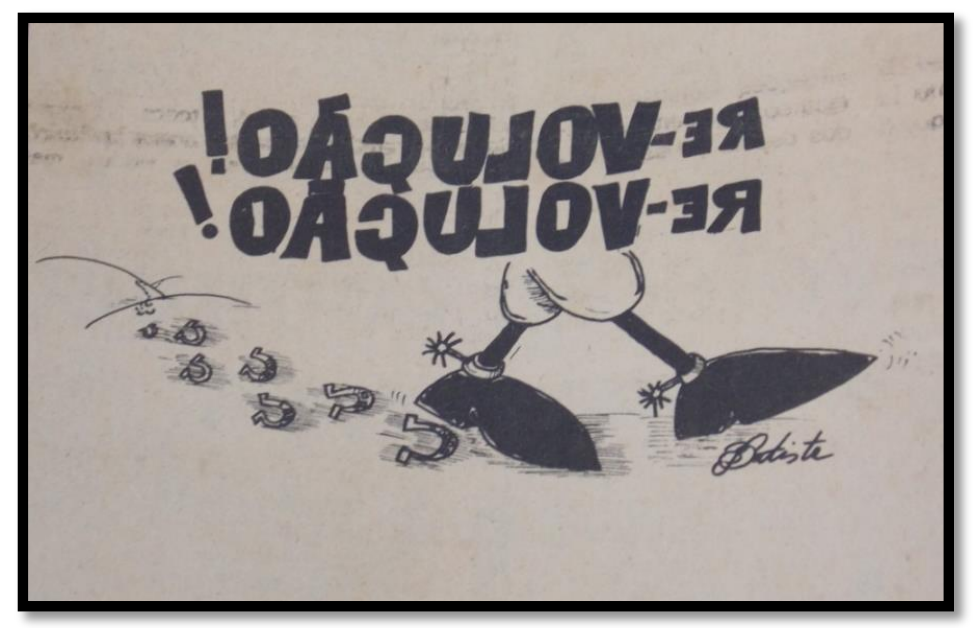


III. Jornal O Dia, 01/02 de abril de 1979.

A palavra escrita ao contrário também nos leva a entender que o movimento de 1964, ao contrário do que foi conceituado pelos articuladores do acontecido, não foi uma revolução, mas um golpe. Bobbio (1998) esclarece a diferença entre Revolução e Golpe, afirmando que:

A Revolução se distingue do golpe de Estado, porque este se configura apenas como uma tentativa de substituição das autoridades políticas existentes dentro do quadro institucional, sem nada ou quase nada mudar dos mecanismos políticos e socioeconômicos (BOBBIO, 1998, p. 1121).

Enquanto Revolução significa "a tentativa, acompanhada do uso da violência, de derrubar as autoridades políticas existentes e de substituí-las, a fim de efetuar profundas mudanças nas relações políticas" (BOBBIO, p. 1121). E o que de fato aconteceu foi um golpe de estado.

Do modo que a charge, aborda não apenas o acontecimento de 1964, como o período em ela foi publicada. Enquanto os passos os rastros do cavalo caminham em uma direção, a revolução que além de estar ao contrário se direciona em outra. Procurando destacar quão distorcida foi a "revolução de 1964".

\title{
CHARGE: DISCURSIVE GENDER AND ITS USE IN A CLASSROOM
}

\begin{abstract}
The cartoons accompany and mark the epoch, serve to understand the critical side of the political and social scene of each society and bring the spirit of a time with its various layers of meaning, whether ideological, cultural or political, these are not just a symbol or subjective manifesto of the cartoonist, but a representation of social groups. The cartoons, as an instrument of reflection and source / object of research can be considered and analyzed as a product of history, as a result of the technique of image production and the press itself. The teacher, in conducting the analysis of cartoons in the classroom, is helping the subjects of learning to appropriate the skills and competences to practice reading and interpreting texts. From the theoretical assumptions of Mikhail Bakhtin (2003), from the perspective of language as social construction, dialogic, and the concepts of discursive genre, the present work will use cartoons as genres that make up the teaching and learning process.
\end{abstract}

KEYWORDS: Charge; Discursive gender; classroom.

\section{Referências}

BAKHTIN, Mikhail. Estética da criação verbal. 4. ed. São Paulo: Martins Fontes, 2003.

BITTENCOURT, Circe Maria Fernandes. Ensino de História: fundamentos e métodos. São Paulo: Cortez, 2004. 
BRESSER- PEREIRA, Luiz Carlos. Os limites da "abertura" e a sociedade civil. In. FLEISCHER, David. Da Distensão à Abertura: As Eleições de 1982. Brasília: Editora Universidade de Brasília, 1988.

BOBBIO, Noberto, MATTEUCCI, Nicola e PASQUINO, Pasquino. Dicionário de polítical. Brasília: Editora Universidade de Brasília, 1 ed., 1998.

FERNANDES, Florestan. A ditadura em questão. São Paulo: T. A. Queiroz, 1982.

FLÔRES, Onici. A leitura da charge Canoas: Ulbra, 2002.

FONSECA, S. G.. A construção de saberes pedagógicos na formação inicial do professor para o ensino de história na educação; In: Ensino de história: sujeitos e práticas. Rio de Janeiro: Manud X: FAPERJ, 2007. (Trabalhos apresentados no V Encontro Nacional Perspectiva de Ensino de História, Ensino de história: sujeitos, saberes e práticas, realizado no Rio de Janeiro, de 26 a 29 de julho de 2004. p. 149 $-156$

A História na educação básica: conteúdos, abordagens e metodologias. Anais do I Seminário Nacional: Currículo em Movimento - Perspectivas Atuais Belo Horizonte, novembro de 2010.

GAWRYSZEWSKI, Alberto. Conceito de caricatura: não tem graça nenhuma. In: Revista Domínios da Imagem, número 02, maio de 2008, Universidade Estadual de Londrina, 2008.

LAJOLO, Marisa. Do mundo da leitura para a leitura do mundo. São Paulo: Ática, 1993.

LEMOS, Renato. Anistia e crise política no Brasil pós-1964. Topoi, Rio de Janeiro, dezembro 2002, pp. 287-313.

LITZ, Valesca Giordano. O Uso da imagem no ensino de História. Universidade Federal do Paraná, Curitiba, 2009.

MIANI, Antonio Rozinaldo. Charge: uma prática discursiva e ideológica. XXIV Congresso Brasileiro da Comunicação - Campo Grande /MS - setembro 2001.

ORLANDI, E. Análise de discurso: princípios e procedimentos. Campinas: Pontes, 2000.

PAIVA, Eduardo França. História \& Imagens. Belo Horizonte: Autêntica, 2002.

ROMUALDO, Edson Carlos. Charge jornalística: intertextualidade e polifonia: um estudo de charges da Folha de S. Paulo. T Maringá: Eduem, 2000.

SCHMIDT, M. A. A formação do professor de história e o cotidiano da sala de aula. In: BITTENCOURT, Circe. O saber histórico na sala de aula. 9 ed. São Paulo: Contexto, 2004.

TEIXEIRA, Luiz Guilherme Sodré. Sentidos do humor, trapaças da razão: a charge. Rio de Janeiro: Fundação Casa de Rui Barbosa, 2005. 
Data de Submissão: 10/11/2017

Data de Aprovação: 27/12/2017 